\title{
Long-Term Outcome of Surgical Treatment in Adolescent Idiopathic Scoliosis
}

\author{
Franz Josef Mueller ${ }^{1}$, Herbert Gluch ${ }^{2}$ and Cornelius Wimmer ${ }^{3}$ \\ ${ }^{1}$ Clinic for Orthopedic and Trauma Surgery, Hospital Barmherzige Brueder, Regensburg, \\ 2,3Department for Spine Surgery and Scoliosis Centre, Clinic Schoen, Vogtareuth,
}

Germany

\section{Introduction}

For the surgical treatment of adolescent idiopathic scoliosis various anterior and posterior procedures and instrumentations were developed. With regard to posterior procedures, two different well-known instrumentations must be distinguished:

With the development of the Harrington rod (Harrington, 1962) a long-segment rod and hook instrumentation was available for the first time, which became the worldwide standard procedure for many years in the surgical treatment of adolescent idiopathic scoliosis. According to a retrospective meta-analysis, Harrington rods were used in more than 85\% of such cases between 1958 and 1993 (Haher et al., 1995). With this instrumentation, frontal correction was achieved primarily by the distraction and elongation of the concave side, and by the compression of the convex side of the curve. The disadvantage of this method was the flattening of the spinal profile (Humke et al., 1995), with less improvement of the rib hump deformity (Aaro \& Dahlborn, 1982; Weatherley et al., 1987). Moreover, there have been reports of high revision rates with the complete removal of the instrumentation due to chronic complaints of the lumbar spine (Padua et al., 2001). The instrumentation has also required postoperatively external stabilisation for about 6 to 12 months with a plaster cast or an orthesis in order to avoid the loss of initial curve correction (Danielsson et al., 2001; Dickson \& Harrington, 1973; Harrington, 1962; Mariconda et al., 2005).

With the development and introduction of a novel double-rod instrumentation by Cotrel and Dubousset (Cotrel \& Dubousset, 1984) about 25 years later, the disadvantages of the Harrington rod seemed to be eliminated. Early results with a small number of patients showed that the instrumentation not only provided better lateral and frontal curve correction, but also a significant correction of vertebral rotation and thus a marked reduction in the cosmetic rib hump deformity (Cundy et al., 1990). Moreover, the instrumentation gives greater primary stability so that postoperative management with an external orthesis was no longer required. On the other side, the surgical procedure requires much greater surgical skill with a long learning curve, especially due to the correct placement of the multiple laminar hooks and the subsequent insertion of the transpedicular screws.

Several other instrumentations (e.g. Luque instrumentation, Lea Plaza frame) (Luque, 1982; Lea Plaza et al., 2004) were introduced and - due to various problems - abandoned, and 
none of these was broadly used for a long period of time. Apart from that, the authors of this chapter conducted literature research (Pubmed) and did not succeed in finding any long-term results for any of the above-mentioned instrumentations.

Different anterior and posterior instrumentations, including minimally invasive or thoracoscopic approaches, were introduced within the last 10 years (Ameri et al., 2008; Asher et al., 2004; Halm et al., 2000; Liljenqvist et al., 2006; Lonner et al., 2006; Reddi et al., 2008; Remes et al., 2004).

Today, transpedicular mono- or poly-axial titanium screws, with different fixation systems e.g. over the top or side loading systems, are mainly used for posterior procedures in order to fuse less vertebral segments and to achieve an increasing curve correction rate with stronger primary stability. For the spine surgeon, however, the surgical principles still remain the same: correction by instrumentation and solid fusion by spondylodesis.

However, what are the concerns and expectations of the patients before and after surgery?

For this reason, 91 adolescent patients and their parents were independently asked to complete a questionnaire regarding their concerns of upcoming scoliosis surgery in a multicentre cross-sectional study (Bridwell et al., 2000). Neurological deficits were the greatest concern of both patients and parents, and the most important expectation and main reason for undergoing surgery was to reduce future pain and disability as an adult.

The short-term results within 2 years postoperatively demonstrated that pain, general selfimage, function from back condition and level of activity improved statistically significantly compared with the preoperative status, but without correlation between the magnitude of curve correction and outcome scores in validated questionnaires (Merola et al., 2002).

However, until 10 years ago, there was no standardised questionnaire available to evaluate the outcome of surgically treated patients for adolescent idiopathic scoliosis, despite the fact that (life) satisfaction and self-esteem are important qualities in social science and daily life.

On the other side, adolescent idiopathic scoliosis by itself has namely a significant negative impact on quality of life and psychological functioning (Kahanovitz \& Weiser, 1989). Moreover, a study reported that scoliosis is a risk factor for depression, no matter what treatment the patients has received, and findings from other studies have indicated that idiopathic scoliosis may have a negative effect on one`s psychological state, development of friendships, and ability to adapt socially (Payne et al., 1997).

Surgical outcomes have traditionally been based on radiographic measures e.g. degree of correction and complications rates. Relatively few studies have had addressed patientfocussed measures. However, all these studies did not use a standardised and validated outcome questionnaire. Therefore, the Scoliosis Research Society charged an outcome committee with the development of a patient-focussed outcome questionnaire to assess the impact of the surgical treatment of adolescent idiopathic scoliosis. This initially developed and validated instrument (Haher et al., 1999) consisted of 24 questions - therefore named SRS-24 - divided into 7 equally weighted domains, which are: pain, general self-image, postoperative self-image, postoperative function, function from back condition, general level of activity, and satisfaction. All responses were rated on a 5 point scale with 5 being the optimal response. Although the SRS-24 is simple, practical, and easy to administer (Merola et al., 2002), there were several concerns that it had low internal consistency for some 
domains. Asher et al. modified it and created the SRS-22, which has 5 domains: function/activity, pain, self-image/appearance, mental health, and satisfaction with management (Asher et al., 2003). The SRS-22 has now become a widely used outcome instrument for evaluating adolescent idiopathic scoliosis, and has been properly validated (Bridwell et al., 2005).

On the other hand, both questionnaires (SRS-24; SRS-22) do not extensively assess mental health and have only very few items related to life satisfaction and self-esteem (Zhang et al., 2011).

No controlled study, at least not in the short-, mid- or long-term period, was found in a systematic PubMed search by Weiss to reveal evidence to support the hypothesis that the effects of surgery as a treatment option for adolescent idiopathic scoliosis is superior to natural history (Weiss, 2008).

Therefore, the author - senior consultant of the well-known and highly esteemed Spinal Deformity Rehabilitation centre in Bad Sorbernheim, Germany - concluded that the indication for the surgical correction of adolescent idiopathic scoliosis is limited to cosmetic reasons in severe cases, but the author did not define and discuss the term "severe" in detail.

Now, the long-term results of two of the authors' studies investigating posterior instrumentation and spondylodesis in patients with adolescent idiopathic scoliosis are presented. One of the two studies was published recently (Mueller \& Gluch, 2009). Furthermore, original papers (exclusively) presenting other long-term results will be compiled in a chronological manner and reviewed critically, without making claims of being complete.

\section{Long-term outcome with the Harrington rod}

\subsection{Background of the Harrington rod}

In 1962 - partially even in 1960 during a lecture at the Annual Meeting of the American Orthopaedic Association - Paul R. Harrington published a paper, in which he was the first to introduce a long rigid instrumentation for the dorsal correction of scoliosis (Harrington, 1962). Up to that date (since 1914), only spondylodesis methods without instrumentation were known, based on a scientific publication from 1924 comprising 59 patients (Hibbs, 1924).

Harrington developed a stainless steel posterior rod system, which used 2 rods and hooks in the frontal spinal plane to create distraction as well as compression in the area of the curvature. In his original landmark paper he described the development and the utilisation of this instrumentation, which started as early as in 1947 and which was completed only in 1960, due to different problems with the instrumentation that required multiple modifications. At that time, the instrumentation had only been used in a few patients (19491954: 19 patients; 1955-1960: 49 patients) with scoliosis secondary to poliomyelitis. After the completion of this development phase, 68 patients were treated with the final rod system in 1960. However, even at that time, there was only little experience with the treatment of patients suffering from adolescent idiopathic scoliosis (Harrington, 1962).

Over time, almost 1,500 scoliosis patients were treated with the Harrington rod between 1961 and 1972, but further modifications of the instrumentation had to be implemented 
between 1960 and 1972 (Harrington \& Dickson, 1973). At that time, the initial long-term results after a follow-up period of at least 5 years showed an unexpected high rate of loss of correction, despite additional spondylodesis (Harrington \& Dickson, 1973).

\subsection{Literature review regarding the Harrington rod}

Although the Harrington rod was worldwide the most frequently used for the surgical correction of adolescent idiopathic scoliosis for more than 2 decades (Haher et al., 1995), the overall long-term results are scanty and are often limited to specific questions. This might be due to the fact that many of these instrumentations were removed after only a few years, routinely or because of complications (Padua et al., 2001).

2011 A recently published retrospective Japanese study (Akazawa et al., 2011) conducted patient follow-up (questionnaire) on only 66 out of 256 patients $(25.8 \%)$ with adolescent idiopathic scoliosis after a period of 21 to 47 years (mean 31.5 years) post surgery. Mean age at the time of surgery was 14.8 years (range 10 to 19 years). In 51/66 cases, a Harrington rod was used for correction, with a variety of anterior and posterior systems being used for the other patients. The average Cobb angle was $69.5^{\circ}$ (preoperatively) and $37.5^{\circ}$ (postoperatively), respectively, equivalent to a correction of $46 \%$. No radiological follow-up was conducted at the time of data collection, and it was not documented whether the instrumentations were still in situ at that time, or if removal had been performed. Furthermore, this study does not contain any information regarding scoliosis curvature or any complication analyses. A significantly worse function and worse self-image (as determined using the SRS-22) was observed in patients when compared to an age-matched control group, but no differences were reported regarding pain and mental health scales. Furthermore, there were no significant differences in the Roland Morris Disability Questionnaire; the mean value was 1.8 points.

The authors from the University Hospital in Chiba, Japan, concluded that surgery had no demonstrable adverse effects on pain or mental health in their patients, although they did have a significantly lower function and lower self-image than healthy controls.

2005 After a minimum of 20 years (range 20 to 27 years) post surgery, Mariconda from the University Hospital Naples, Italy, retrospectively tried to evaluate the outcome of 62 patients treated with a single Harrington rod between 1976 and 1981 (Mariconda et al., 2005). All patients were fused by autologous bone grafts, and postoperatively they wore a plaster cast for a minimum of 6 months, followed by a plastic brace for an additional 6 months. For different reasons, only 16 out of 62 patients $(26 \%)$ participated in the clinic and radiographic study: At follow-up, the Cobb angle of the main curve still showed an average correction rate of $41 \%$, and the average SRS-24 score was 101 (78-110) out of a maximum of 120 points.

Compared to a non-scoliosis control group, the only significant difference was aesthetic discomfort, reported by 10 out of 16 patients and only 2 out of 24 controls. No further significant differences in the individual domain scores were observed. Therefore, the authors considered Harrington fusion as a procedure that produces a long lasting high degree of self-reported postoperative satisfaction.

2003 A further study from Helsinki, Finland, investigated 78 out of 98 patients (80\%) with adolescent idiopathic scoliosis and Harrington rod instrumentation with a follow-up of 20.8 
years postoperatively (Helenius et al., 2003). However, all the rods were removed routinely only 2 years after index surgery, if there was no pseudarthrosis. Preoperatively, there was an average thoracic $\mathrm{Cobb}$ angle of $53^{\circ}$; at the time of follow-up the average thoracic curve was $45^{\circ}$ and the correction rate was only $15 \%$ at the time of follow-up. The frontal lumbar correction was only $14 \%$. Frontal decompensation $(>20 \mathrm{~mm}$ ) was found in 9 out of 78 patients $(12 \%)$. There was an overall complication rate of $12 \%$ but acute or late deep infection was not documented in any patient. A reason for this might have been the complete removal of the implants, which naturally avoids the attachment of bacteria to the implant. The average SRS questionnaire score was 97 points, but 10 patients (13\%) complained of back pain often or very often. Individual items of the SRS questionnaire such as patient satisfaction were not presented.

2002 In 2002, a German study group from Muenster (Goetze et al., 2002) published the quality of life of 82 out of 104 patients treated with Harrington rods between 1979 and 1989. The aim was, to analyse long-term health-related quality of life and low back pain with a minimum of 10 years follow-up. After an average of 16.7 years (range 11 to 22 years) post surgery, quality of life was measured with the Short Form-36 health profile (Ware \& Sherbourne, 1992). Low back pain was assessed using the Roland-Morris Questionnaire (Fairbank et al., 1980), and the radiological parameters were analysed longitudinally.

The mean Cobb angle in right thoracic scoliosis was $63.1^{\circ}$ (range, 40-110 ${ }^{\circ}$ ) before surgery and $30.6^{\circ}$ (range, $14-70^{\circ}$ ) after surgery. The average primary correction was $51.5 \%$. In double major curves, the right thoracic curve was corrected from $61^{\circ}$ to $36.9^{\circ}$ (39.5\% correction) and the lumbar curve from $55^{\circ}$ to $33.5^{\circ}(39.1 \%)$. In double thoracic curves the right thoracic curve was corrected from $61^{\circ}$ to $30.3^{\circ}(50.3 \%)$ and the left high thoracic curve was corrected from $38.5^{\circ}$ to $29.5^{\circ}(23.4 \%)$. At 5 years, the mean Cobb angles were not significantly different from those at one year post surgery.

In comparison with an age-matched healthy population, there was no significant difference in the physical Short Form-36 scale, but surgically treated patients showed significantly lower scores in the psychological Short Form-36 scale. Vitality, general mental health, and role activities because of emotional problems were significantly different from those of the age-matched population. 65 out of 82 patients $(79 \%)$ reported no or occasional back pain in the Roland-Morris Questionnaire. 5 patients $(6.1 \%)$ reported chronic back pain. Neither patient age at the time of surgery nor the time of the follow-up, type of scoliosis, or extent of fusion were associated with health-related quality of life or pain. The size of the pre- and postoperative curves and pre- and postoperative rib cage deformities did not correlate with the data of the Short Form-36 scale and the Roland-Morris Questionnaire.

Therefore, the authors concluded that, in comparison with the age-matched population, the long-term effect of surgery does not affect the physical quality of life. The psychological health status, however, has been significantly impaired. Neither the type of curve, nor the size of scoliosis or rib cage deformity influences the data.

It was a considerable weakness of this study that the complication and/or surgical revisions rates were not presented.

2001 Until 2001, no results on the outcome in terms of validated health-related quality of life were presented for patients treated for AIS. For the first time, Danielsson et al. from 
Gothenburg, Sweden, published a consecutive series of patients treated between 1968 and 1977 by using Harrington rods, and an additional brace treatment group (Milwaukee or Boston brace) (Danielsson et al., 2001). 146 of the surgical treated patients were followed for a period of at least 20 years (mean 23.3 years) after the completion of the treatment before the patients reached 21 years of age. Moreover, an age- and sex-matched control group of 100 persons was randomly selected and underwent the same examinations.

The health-related quality of life results showed no differences in terms of sociodemographic data (e.g. marriage or childbearing) between the three groups. The surgical treatment and brace treatment groups had a slightly, but significantly reduced, physical function using the SF-36 (Ware \& Sherbourne, 1992) subscales as well as the Oswestry Disability Back Pain Questionnaire (Fairbank et al., 1980) compared to the healthy controls (100 patients). No correlation was found between the outcome scores and curve size after treatment, curve type, total treatment time or age at completed treatment. In conclusion, patients treated for AIS were found to have approximately the same healthrelated quality of life as the general population.

It must be emphasised that the publication of Danielsson et al. has been an excellent although retrospective - long-term investigation on AIS treatment, and there are no other crucial aspects to criticise.

2001 In the same year, Padua et al. from Rome, Italy, published a follow-up of only 70 out of a total of 184 patients (38\%) with a Harrington rod (Padua et al., 2001). The average followup was 23.7 years. In 48 out of 70 patients $(68.8 \%)$ the Harrington rod had already been removed for a wide range of reasons: 10 times $(14 \%)$ because of late surgical site pain, 3 times because of implant fracture, 5 times because of the worsening of the curve and 30 times for causes that were not specified in detail. Radiologically, the average preoperative Cobb angle was $58.8^{\circ}$, and immediately postoperatively the average was $22.8^{\circ}$. At the follow-up, the average Cobb angle was $43.4^{\circ}$, which corresponds to a loss of $20.6^{\circ}$ or $47.9 \%$ of the initial correction. The reasons for this remain unclear: no pseudarthrosis was seen in this study and patients without a Harrington rod did not show a significantly greater loss of correction than those with the instrumentation still in situ. The clinical outcome was recorded with the SF-36 (Ware \& Sherbourne, 1992), and the overall outcome was similar to that of a normal population. However, on further questioning, only 46 patients $(66 \%)$ were satisfied with the operation overall and only 17 patients $(24 \%)$ rated it as excellent or good with regard to aesthetic aspects.

2000 One year before, Cook et al. from the University hospital in Kansas, Canada, investigated 64 patients over an average postoperative period of 142 months (range 24 to 192 months) with an isolated inquiry for the revision rate compared to 2 other instrumentations (Cook et al., 2000). 12 out of 64 patients (19\%) with a Harrington rod had to be re-operated, on average 55 months (range 20 to 97 months) post surgery. The most frequent indication was pseudarthrosis ( 5 out of $12 ; 8 \%$ ), followed by late surgical site pain (4 out of $64 ; 6 \%$ ).

1995 In 1995, Connolly et al. from Ontario, Canada (Connolly et al, 1995) were able to follow-up on 83 patients with AIS by means of a questionnaire, with radiological imaging in only 55 of these patients $(66 \%)$, on average 12 years after Harrington rod instrumentation. The questionnaire yielded an excellent or good result for 55 of 83 patients $(66 \%)$, and 28 patients $(34 \%)$ assessed the result as fair or poor. 14 patients 
$(17 \%)$ did not think that the goals of the initial operation had been accomplished. $76 \%$ of the patients also complained of lumbar back pain, and this result was thus markedly worse compared to the control group. A total of 18 patients $(22 \%)$ also required surgical revision for various reasons.

1995 Humke (Humke et al., 1995) investigated 63 out of 72 patients (86\%) with adolescent idiopathic scoliosis treated between 1968 and 1977 at the Schulthess Hospital at Zuerich, Switzerland. All operations were performed by the senior author of the study. Fusion included 10.5 segments on average, but the fusion technique was not explained in the publication. Re-examination included clinical and radiological assessments after a mean period of 12.3 years post surgery compared to Cotrel-Dubousset instrumentation. All patients underwent additional brace treatment lasting 8 months on average (range 6 to 11 months). Preoperatively, the average Cobb angle of the main curve was $67.8^{\circ}$, with postoperative correction to $33^{\circ}$. At the follow-up, there was a high loss of correction of $20.7 \%$ compared to the correction achieved postoperatively. $40 \%$ of the patients also had a clinical flat back, but this was not associated with clinical back pain. However, lateral radiological imaging was not conducted. Subjectively $86 \%$ of the patients were satisfied or very satisfied with the outcome of the operation but $10 \%$ of the patients complained of severe lumbar back pain.

1990 The authors (Dickson et al., 1990) from Houston, Texas, USA, sent a questionnaire to 206 consecutive patients who were operated on for idiopathic scoliosis by Paul R. Harrington between 1961 and 1963. 83\% of the patients responded to the questionnaire, which consisted of five sections: demographic data, activities of daily living, back symptoms (pain and fatigue), a history of personal and family health, and a personal assessment of the back. 111 out of 206 patients also sent recent radiographs. A control group, comprising 100 individuals who did not have scoliosis, was given the same questionnaire.

The results showed, that patients in the study group had more pain in the interscapular and thoracolumbar region compared with the control group, but there was no difference with respect to pain in the lumbosacral area or the low back. Neither pain nor fatigue was related to the type of curve, the preoperative degree of curvature, the degree of curvature as seen in the most recent radiograph, the extent of fusion into the lumbar spine, or the presence of a broken rod. 21 years after surgery, the patients were functioning quite well compared with the control subjects.

1983 As early as in 1983, Cochran et al. (Gothenburg, Sweden) were the first to publish medium- to long-term results of 95 out of 100 patients (Cochran et al., 1983): 52 of these patients were treated with two rods between 1968 and 1973, and 48 patients were treated with only one rod between 1973 and 1975. Fusion was performed in patients of the first group only in a second procedure one week post surgery, and all patients received an additional Milwaukee Corset post surgery.

At least 5 years (average: 9 years) post surgery, radiological findings showed a correction rate of $50 \%$ for the main curvature, although there was a significant lateral flattening of the lumbar spine. The patients did not show physical impairment or an increase of back pain when compared to a control group of 85 healthy persons. 


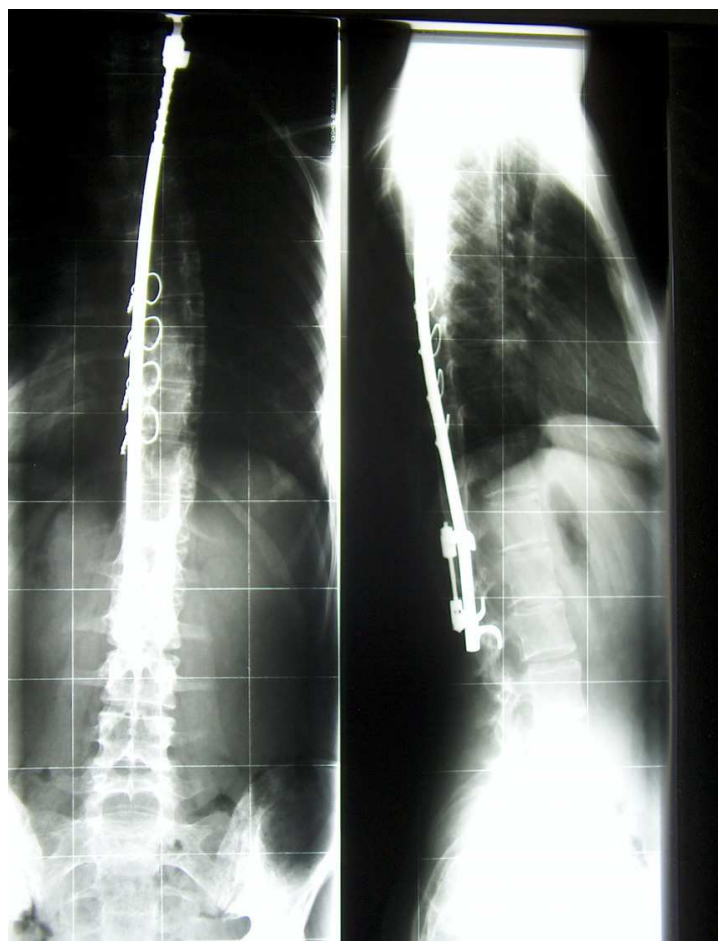

Fig. 1. X-ray of Harrington rod instrumentation with additional wires

\begin{tabular}{|c|c|c|c|c|c|}
\hline $\mathbf{A}$ & B & $\mathrm{C}$ & $\mathbf{D}$ & $\mathbf{E}$ & $\mathbf{F}$ \\
\hline 2011 & Akazawa & 66 & 31 & $\begin{array}{l}\text { SRS-22: no adverse effects on pain or } \\
\text { mental health }\end{array}$ & $\begin{array}{l}\text { significant lower function and self } \\
\text { image }\end{array}$ \\
\hline 2005 & Mariconda & 24 & 23 & $\begin{array}{l}\text { SRS-24: high degree of self-reported } \\
\text { satisfaction }\end{array}$ & aesthetic discomfort \\
\hline 2003 & Helenius & 78 & 21 & SRS: 97 points & \\
\hline 2002 & Goetze & 82 & 17 & $\begin{array}{l}\text { SF-36: surgery does not affect physical } \\
\text { quality of life }\end{array}$ & $\begin{array}{l}\text { psychological health status is } \\
\text { significantly impaired }\end{array}$ \\
\hline 2001 & Danielson & 146 & 23 & $\begin{array}{l}\text { SF-36: approximately same quality of life } \\
\text { as the general population }\end{array}$ & slightly reduced physical function \\
\hline 2001 & Padua & 70 & 24 & $\begin{array}{l}\text { overall outcome similar to the normal } \\
\text { population }\end{array}$ & $\begin{array}{l}\text { only } 66 \% \text { were satisfied with the } \\
\text { surgery }\end{array}$ \\
\hline 1995 & Connolly & 83 & 12 & $66 \%$ with excellent or good results & $\begin{array}{l}34 \% \text { assessed the result as fair or } \\
\text { poor }\end{array}$ \\
\hline 1995 & Humke & 63 & 12 & $86 \%$ were satisfied with the outcome & $\begin{array}{l}10 \% \text { patients complained of severe } \\
\text { lumbar back pain }\end{array}$ \\
\hline 1990 & Dickson & 171 & 21 & patients were functioning quite well & $\begin{array}{l}\text { more pain in the interscapular and } \\
\text { thoracolumbar region }\end{array}$ \\
\hline 1983 & Cochran & 95 & 9 & no reduced activity, no back pain & $\begin{array}{l}\text { significant reduction of lumbar } \\
\text { lordosis }\end{array}$ \\
\hline
\end{tabular}

Table 1. 
Overall summaries of the different studies on the Harrington rod
A: year of publication
B: author's name
C: number of patients
D: mean of follow-up in years
E: positive conclusions
F: negative conclusions

\section{Long-term outcome of Cotrel-Dubousset (CD) instrumentation}

\subsection{Background to CD instrumentation}

In 1984, Cotrel Y und Dubousset J - two orthopaedic surgeons - published a paper in the French language, in which they presented their new dorsal implant for scoliosis treatment for the first time (Cotrel \& Dubousset, 1984). Theoretically, this instrumentation should provide a better coronal deformity correction than the Harrington rod. However, the axial correction or derotation potential is entirely attributable to the improvement in apical translation (Takahashi et al., 1997) and, therefore, has not been as effective as initially hoped. Moreover, the instrumentation requires greater surgical skill with extended surgical time and higher blood loss than a Harrington procedure. So far, very few long-term results have been published for the $\mathrm{CD}$ instrumentation although it has been available worldwide as a device now for over 25 years.

Some outcome studies were reviewed that did not meet our criteria for long-term outcome noted above but were considered, especially with regard to late deep infection and late surgical site pain, as we have seen in our own study patients with CD instrumentation.

\subsection{Authors' study results on CD instrumentation}

Between March 1990 and September 1992, a total of 40 consecutive patients with adolescent idiopathic scoliosis underwent surgical correction for adolescent idiopathic scoliosis with Cotrel-Dubouset instrumentation (Sofamor). This is a double rod system made of steel, which allows segmental fixation through laminar hooks and/or conical pedicle screws. During this period, no other posterior procedure was employed for the surgical treatment of adolescent idiopathic scoliosis. Before this period, we used Harrington rods and Luque instrumentation for this indication, while after the period, only instrumentation made of titanium alloy was used.

The indication for surgery was the progression of the scoliosis and/or a main curve of more than $45^{\circ}$ in the frontal plane. The exclusion criteria were spinal abnormalities, e.g. wedgeshaped vertebrae, or previous surgical procedures such as Ascani rod or anterior correction spondylodesis. Anterior release to mobilise a rigid main curve was not an exclusion criterion.

Additional procedures or measures such as rib osteotomy or thoracoplasty were not performed in any of the 40 patients. For preparation and mobilisation for the operation, all of the patients carried out Cotrel self-extension over a period of 2 to 3 weeks and halo extension was not applied to any patient. Immediately preoperatively and if necessary intraoperatively, all the patients were given intravenous cephalosporin as prophylactic antibiotic. 
The surgical procedure, after the exposure of the spine, involved the mobilisation of the scoliosis initially by the resection of the spinous processes, decortication of the laminae, facet joint cleaning and division of the ligamentum flavum on the concave side of the curvature. This was followed by the correction of the scoliosis by inserting the hooks and pedicle screws with loading of the two anatomically shaped vertical rods with rotation in situ with additional compression or distraction of segments as needed.

No spines were instrumented and fused to the sacrum. Two transverse connectors were placed cranially and caudally between the two vertical rods in all of the patients. A wake-up test was performed to check the intraoperative neurology after insertion of the vertical rod on the concave side; neurophysiological monitoring was not employed. For spondylodesis only homologous bone material reduced to chips was employed. All patients received autologous blood with or without cell saver, no patient received blood products that were not autologous. All patients were mobilised in principle from the $2^{\text {nd }}$ or $3^{\text {rd }}$ postoperative day without a corset.

For the study, the demographic data of all 40 patients were initially recorded from the medical files: age at the time of surgery and sex, operation time, blood loss and documented complications. All pre- and postoperative spinal radiographs in both planes (with the patients standing on cassettes that were 36 inches long) were then analysed with regard to the following parameters: curve patterns were classified by the method based on King-Moe (King et al., 1983) and Scoliosis research society terminology; measurement of the frontal main and secondary curves using the Cobb method (Cobb, 1948); number and height of the fused vertebra and number of hooks and pedicle screws employed.

Following the evaluation of the demographic and radiological data in 2005, it was attempted to invite the patients for a follow-up; however, it was only possible to contact a few patients, others refused clinical radiological follow-up for different reasons, and it was not possible to collect clinical data from more than 14/40 (35\%) patients.

\section{Results}

The demographic data included 40 patients (28 women, 12 men), with an average age at the time of surgery of 16.0 years (range: 13 years to 21 years). Posterior fusion with the CD instrumentation was performed in all cases. Additionally, 3 out of $40(7.5 \%)$ patients had anterior release preoperatively because of a severe main thoracic curve (average $81^{\circ}$ ). The average blood loss was $2770 \mathrm{ml}$, and average operation time was $325 \mathrm{~min}$. Fusion with the CD instrumentation included 13.4 vertebrae (range 8 to 16) on average. The two rods were fixed by the hybrid technique, a combination of hooks and pedicle screws, with an average of 8 hooks and 4 screws per patient. A total of 325 hooks and 161 pedicle screws were inserted in 40 patients. The pedicle screws were inserted mainly in the lumbar region of the instrumentation.

According to the SRS terminology there were 23 right thoracic, 10 double major curves, 4 thoracolumbar, and 3 left thoracic curves. According to the King-Moe classification [12], 17 patients had type II curves; 7 patients type III, and 8 patients type IV curves.

There was no direct or indirect operative mortality. Furthermore, there was no permanent neurological complication. In one case, surgical correction was stopped incompletely because of massive bleeding, and then the correction was successfully concluded 14 days later. 
According to the medical files, 21 out of 40 patients (52.5\%) received one or more operative revisions, for a total of 23 surgical revisions:

Within the first 30 days post surgery, 3 out of 40 patients $(7.5 \%)$ received early operative revision for the dislocation of hooks or rods.

At an average of 45.7 months (range 11 to 142 months), 19 out of 40 patients (47.5\%; including 2 patients with early revision) received late operative revisions.

At this occasion, we documented the revision rate of the highest significance ( 9 out of 16 procedures; 56\%), not in the first year of introduction (1990) but rather for 1992, the third and last year of application. Despite thorough data analysis, we could not find any explanations for this.

The reasons were late infection (10 out of 40 patients; $25 \%$ ) with the development of fistulae (7 cases) or putrid secretion (3 cases), which was resolved with the complete removal of instrumentation after all. We documented 5 out of 7 fistulae at the distal end of the instrumentation. The average time until revision was 35.5 months (range 14 to 56 months) after CD instrumentation. There were no bacteriological findings of any pathogens after a maximum time of cultivation of 48 hours.

Furthermore, complete implant removal was necessary in 8 out of 40 patients (20\%) for late operate site pain (LOSP). No infections or non-unions were detected intraoperatively, but there was a partial implant loosening in the caudal section of the implant in 6 cases, including corrosion in 2 out of 6 cases and broken cranial transverse connectors in 2 other cases. The average time until removal of instrumentation was 62.7 months (range 18 to 146 months) postoperatively.

Moreover, one more patient received partial device removal for prominent instrumentation 11 months postoperatively.

Altogether, only 22 out of $40 \mathrm{CD}$ instrumentations (55\%) were still in situ at the time of follow up.

\section{Results for SRS-24}

14 out of 40 patients (35\%) completed the SRS-24 questionnaire after a mean of 14.3 years postoperatively. In the SRS-24 questionnaire, the total score averaged 93.3 points out of a maximum 120 points (min. 71 to max. 106 points) at the follow-up. The analysis of the questionnaire showed no significant differences between the 5 patients with instrumentation still in situ (average 96.4 points) and the 9 patients after the removal of the instrumentation (average 91.5 points).

\section{Conclusions}

In summary, and for the first time, we documented a very high surgical revision rate for CD instrumentation in the treatment of adolescent idiopathic scoliosis after long-term followup. The reasons for this high rate of revisions due to fistulae, infection, and late surgical site pain remain unclear.

\subsection{Literature review to CD instrumentation}

2007 In 2007, Boss et al. retrospectively investigated 54 consecutive patients who underwent CD instrumentation for right thoracic scoliosis at the University Hospital in Iowa, USA, 
between 1986 and 1991 (Boss et al., 2007). The CD was applied exclusively only with hooks by the senior author, and the patients had mobilisation without the use of a brace. The overall follow-up rate was $96 \%$ at an average of 79 months postoperatively, however the vast majority of patients could not be located or brought back for a 10 year follow-up, therefore only 38 out of 54 patients $(70 \%)$ completed a self-administered - but not validated - questionnaire, and only 14 out of 54 patients (26\%) had a follow-up of more than 10 years.

Radiologically, there were 18 King type 2, 19 Type 3, 5 type 4, 3 type 5 and 9 double major frontal curves. The average coronal Cobb angle of the primary thoracic curve was $55^{\circ}$ preoperatively, $17^{\circ}$ immediately postoperatively, and $22^{\circ}$ at the latest follow-up. The lumbar curve (secondary or double major) averaged $40^{\circ}$ preoperatively, $21^{\circ}$ postoperatively and $23^{\circ}$ at the latest follow-up. In 7 cases there was a loss of correction of the major curve of more than $10^{\circ}$, in which the authors concluded that this was due to various reasons. The results reflected that all the patients were doing well and had no complaints with regard to work or sporting activities. Moreover, there were no apparent non-unions, infections or neurological complications. Only one patient needed the partial removal of the instrumentation due to an irritated bursa over a prominent hardware.

In summary, the authors from the Iowa University Hospital, USA, concluded that CD provides encouraging clinical and radiographic results at an average follow-up of 7 to 9 years. Moreover, satisfaction, functional status and subjective cosmetic improvements were high.

2007 In the same year, a study group from Oslo, Norway, published their single centre results of CD instrumentation 10 years after surgery (Bjerkreim et al., 2007). The study included a total of the first 100 consecutive patients all with a single primary curve treated between 1989 and 1995. The average number of segments fused was 9.3. All the patients were mobilised without a brace. After 2 years of prospective follow-up, the correction rate of the primary curve was still $64 \%$ without a significant loss of correction and solid fusion, but within this period 5 out of 100 instrumentations (5\%) were completely removed for suspected infection, without any evidence for bacteria. All wounds healed primarily after the removal of the instrumentation. Pseudarthrosis was not detected in any of the 100 patients.

Eventually, 10 years after surgery a total of 86 out of 100 patients (86\%) answered a questionnaire mailed to the patients: $97 \%$ considered back function as excellent, good or fair, and $96 \%$ would have done the operation again. Scores for EuroQol (EuroQol; 1990) and Oswestry Disability Index (Fairbank et al., 1980) were within the normal range. However, $45 \%$ of the patients had consulted a physician or received physiotherapy for back pain during the last year before the follow-up.

2006 Weigert et al. conducted a study to assess the outcome after treatment for adolescent idiopathic scoliosis by means of the SRS-24 questionnaire (Weigert et al., 2006). 118 patients from a single centre, treated between 1987 and 1997, were included. 44 patients were treated with a Boston Brace only, 41 had surgery above all with CD instrumentation, and 33 were treated with a brace and surgery. At the follow-up, the re-operation rate was $21.6 \%$ (16 patients) for different reasons, especially due to abscess and fistula (5 patients). Patients with surgical complications had a significantly lower level of satisfaction, all other domain 
scores were unaffected by this factor and were similar to the scores of patients without complications.

The authors' overall conclusion of this study indicates that adolescent idiopathic scoliosis thrive after completed treatment, and the different treatment modalities do not clearly differ with respect to total SRS 24 outcome scores. Moreover, the Boston brace treatment does not permanently impair quality of life, whether applied alone or before surgery, and that combined treatment does not need to be regarded as a double burden with long-lasting negative effects on quality of life.

2003 In 2003, Helenius et al. investigated 57 out of 71 patients $(80 \%)$ with AIS and CD instrumentation over a mean period of 13.0 years post surgery (Helenius et al., 2003). Preoperatively, the average frontal thoracic Cobb angle was $55^{\circ}$. At the time of the followup, the average thoracic curve was $32^{\circ}$ so that the correction rate was $42 \%$. The frontal lumbar curve showed an average correction of $32 \%$ at the time of the follow-up and frontal decompensation (> $20 \mathrm{~mm}$ ) was found in $7 \%$ of the patients. The documented complications were one case of acute $(1.7 \%)$ and 3 cases $(5.3 \%)$ of late deep infection, but prophylactic antibiotics (single shot) were not given. Clinically the average SRS score was 97 points and 6 patients $(11 \%)$ reported back pain often or very often.

2003 Bago et al. from Barcelona, Spain, presented a survivorship analysis of CD instrumenation treated in the surgical treatment of idiopathic scoliosis (Bago et al., 2003). Reoperation, usually the removal of instrumentation, had to be performed in 23 of 110 patients $(21 \%)$ a mean of 56.7 months post surgery. The reason for the majority of reoperations was late infection (10 patients; $9 \%)$, followed by mechanical failure (6 patients), LOSP (4 patients) and acute infection (3 patients).

2000 Cook et al. investigated 49 patients a mean of 105 months post surgery with regard to the isolated question of the revision rate (Cook et al., 2000). 12 out of 49 patients (24\%) had to be re-operated on 41 months (range 20 to 71 months) following index surgery. The indications were late surgical site pain (6 out of 49 patients, 12\%), prominently or improperly placed implant ( 2 patients), pseudarthrosis (1 patient) and late deep infection (1 patient).

1999 In 1999, Clark and Shufflebarger from Miami, USA, retrospectively investigated 917 out of total 1,247 patients with CD instrumentation especially for late deep infection (Clark \& Shufflebarger, 1999). A total of 22 patients were documented. The initial symptom was a fistula or a fluctuant swelling an average of 3.1 years post surgery (1.2 - 8.5 years). In specimens from these patients cultured only 72 hours, 1 out of 10 was positive. Of those cultured for 7-10 days (the last 12) 11 were positive, usually for low-virulence skin organisms. After surgery, patients received antibiotics parenterally for 48 hours and orally for 7 days. In all cases, complete instrumentation removal was done well. The authors concluded, that late-appearing infection can be treated with instrumentation removal, primary skin closure, and short-term oral antibiotics. Moreover, the infections affect soft tissue, and not the bone.

1998 In 1998, Lenke et al. evaluated the radiographic results of CD instrumentation in 76 patients who had been surgically treated in their department and who were followed for an average period of 6 years (Lenke et al., 1998). Comparison of radiographs showed that no patient had lost any correction in the frontal plane at the levels with instrumentation, and 75 
out of 76 patients had no change in the thoracic or lumbar sagittal alignment at the levels with or without instrumentation. Only 1 patient received surgical revision for the loss of correction, and no further complication was reported. 63 out of 76 patients (85\%) responded to a non-validated questionnaire assessing the clinical status. The authors from the University Hospital St. Louis, Missouri, USA, reported that the outcome was favourable with regard to function, cosmetic appearance, and general satisfaction with the surgical result. 24 out of 76 patients (38\%) reported occasional pain in the spine, but 62 out of 63 patients (98\%) would have the operation again.

1997 Takahashi et al. performed a study focusing on postoperative changes in the lumbar spine in 30 patients who had been treated with CD instrumentation (Takahashi et al., 1997). They reported that the prevalence of low back pain increased from $3 \%$ before surgery to $20 \%$ during the follow-up. However, in none of the patients was the pain so severe that specific treatment was required. From their data, the authors concluded that the overall clinical and radiographic results were satisfactory, but the unfused lumbar segments requires careful surveillance.

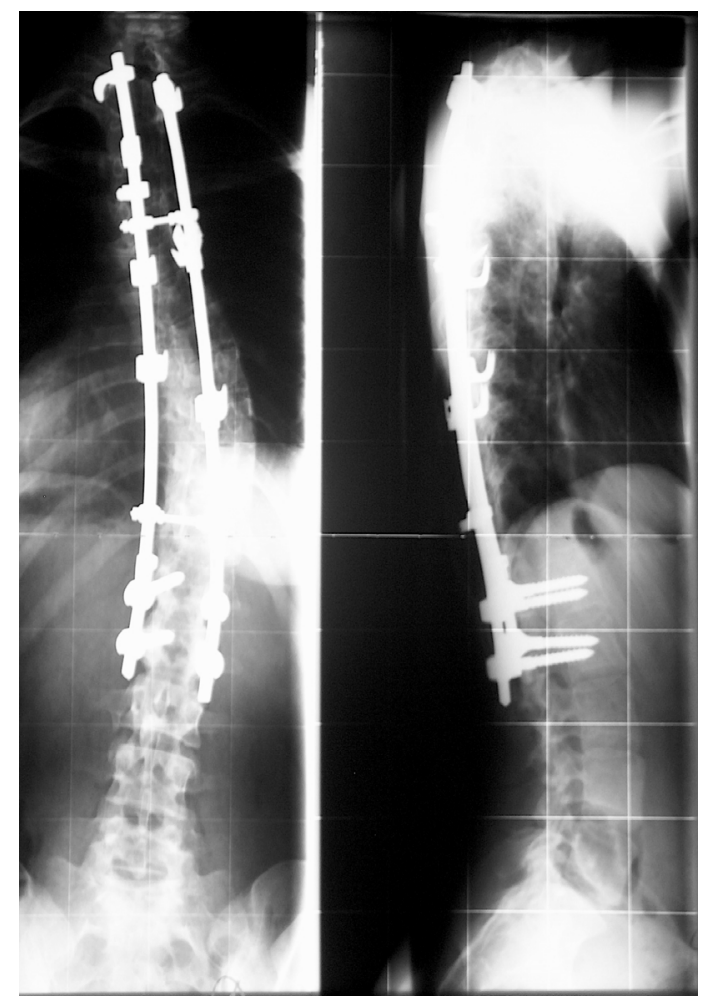

Fig. 2. X-rays of CD instrumentation with hooks and pedicle screws 


\begin{tabular}{|c|l|c|c|l|l|}
\hline A & \multicolumn{1}{|c|}{ B } & C & D & \multicolumn{1}{|c|}{ E } & \multicolumn{1}{|c|}{ F } \\
\hline 2007 & Boss & 38 & 7 & $\begin{array}{l}\text { satisfaction, functional status and subjective } \\
\text { cosmetic improvement was high }\end{array}$ & none \\
\hline 2007 & Bjerkreim & 86 & 10 & scores for EuroQol were within the normal range & $\begin{array}{l}\text { 45\% had back pain within } \\
\text { the last year }\end{array}$ \\
\hline 2006 & Weigert & 41 & $>2$ & SRS-24: fair or better in all domains & $\begin{array}{l}\text { re-operation rate was } 21.6 \% \\
\text { often or very often }\end{array}$ \\
\hline 2003 & Helenius & 57 & 13 & SRS: 97 points & re-operation rate was 21\% \\
\hline 2003 & Bago & 110 & 5 & $?$ & re-operation rate was $24 \%$ \\
\hline 2000 & Cook & 49 & 9 & $?$ & $\begin{array}{l}38 \% \text { reported occasional } \\
\text { pain in the spine }\end{array}$ \\
\hline 1998 & Lenke & 76 & 6 & outcome was favourable & $\begin{array}{l}\text { 20\% prevalence of low back } \\
\text { pain }\end{array}$ \\
\hline 1997 & Takahashi & 30 & 6 & the overall clinical results were satisfactory & \\
\hline
\end{tabular}

Table 2.

Overall summaries of the different studies on the CD instrumentation
A: year of publication
B: author's name
C: number of patients
D: mean of follow-up in years
E: positive conclusions
F: negative conclusions

\section{Long-term outcome of other instrumentation technologies}

\subsection{Authors' study results}

In the scoliosis centre of the Behandlungszentrum Vogtareuth, Germany, a double-rod system made of titanium alloy has been used since 1993 for the surgical correction of scoliosis, which also allows three-dimensional correction through segmental hooks and/or transpedicular screws (System WSI Titan, Peter Brehm Chirurgie Mechanik, 91084 Weisendorf, Germany). With regard to long-segment implants made of titanium in the treatment of AIS, to our knowledge there are so far no radiological and clinical long-term results of at least 10 years on average in the Pubmed literature.

The aim of our study was, therefore, to examine the efficacy and safety of this titanium instrumentation in AIS and to compare the results achieved with the two standard procedures referred to above. Our hypothesis was that titanium achieves the same or better long-term results in the surgical treatment of AIS compared to the data in the literature with regard to the Harrington rod or the $\mathrm{CD}$ instrumentation.

Between January 1993 and March 1996, a total of 50 patients with AIS had surgical correction with the titanium WSI (Wirbelsäulenimplantat; the German language for the spine implant).

This is a double rod system made of pure titanium (rods) with a diameter of 6 or $7 \mathrm{~mm}$, which allows segmental fixation through lamina hooks and/or conical pedicle screws (TiAl6V4) (Figure 1). 
The indication for operation was the progression of scoliosis and/or a main curve of more than 45 degrees in the frontal plane. During the study period, no other posterior procedure was employed for the surgical treatment of AIS. The exclusion criteria were spinal abnormalities, e.g. wedge-shaped vertebra, or previous surgical procedures such as Ascani rod or anterior correction spondylodesis. Anterior release to mobilise a rigid main curve was not an exclusion criterion. Additional procedures or measures such as rib osteotomy or thoracoplasty were not performed in any of the 50 patients. For preparation and mobilisation for the operation, all of the patients carried out Cotrel self-extension over a period of 2 to 3 weeks, and halo extension was not applied to any patient. Immediately preoperatively - and if necessary intraoperatively - all patients were given intravenous cephalosporin as prophylactic antibiotic. Nearly all the surgical procedures were performed by the senior author (H.G.). The surgical procedure, after the exposure of the spine, involved the mobilisation of the scoliosis initially by the resection of the spinous processes, decortication of the laminae, facet joint cleaning and the division of the ligamentum flavum on the concave side of the curvature. This was followed by the correction of the scoliosis by inserting the hooks and pedicle screws with the loading of the two anatomically shaped vertical rods with rotation in situ with additional compression or distraction of segments as needed. No spines were instrumented and fused to the sacrum or the fifth lumbar vertebra. A transverse connector was placed cranially and caudally between the two vertical rods in all of the patients. A wake-up test was performed to check intraoperative neurology after the insertion of the vertical rod on the concave side; neurophysiological monitoring was not employed. For spondylodesis, only local bone material reduced to chips was employed. An iliac crest autograft or homologous bone was not used in any patient. All patients received autologous blood with or without cell saver, no patient received blood products that were not autologous. All patients were mobilised in principle from the $2^{\text {nd }}$ or $3^{\text {rd }}$ postoperative day without a corset.

For the study, the demographic data of all 50 patients were initially recorded from the medical files: age at the time of surgery and sex, operation time, blood loss and documented complications. All pre- and postoperative spinal radiographs in both planes (with the patients standing on cassettes that were 36 inches long) were then analysed with regard to the following parameters: curve patterns were classified by the method based on King-Moe (King et al., 1983) and the Scoliosis research society terminology; measurement of the frontal main and secondary curves using the Cobb method (Cobb, 1948) number and height of the fused vertebra and number of hooks and pedicle screws employed.

Frontal balance, determined on the basis of the horizontal distance, in millimetres, from the centre of the $\mathrm{C} 7$ vertebral body to the centre of the sacrum. Imbalance was defined as a horizontal distance of $>20 \mathrm{~mm}$. Apical vertebral translation was defined as the distance, in millimetres, between the plumbline and the mid-portion of the vertebral body at the apex of the curve. The sagittal thoracic kyphosis angle was measured between T5 and T12 and the lordosis angle between L1 and S1, also using Cobb's method'. Attention was also paid to radiological complications, such as rod fracture, pedicle screw fracture, or hook dislocation. Because of the relatively low accuracy of the measurements, the radiological measurement of vertebral rotation or clinical measurement of ribcage projection was omitted. CT scans were not performed routinely, neither pre- nor postoperatively.

Following the evaluation of the demographic and radiological data between January 2005 and August 2005, the patients were invited by telephone to attend the follow-up, and the 
above-described radiological examinations were repeated and compared with previous films. The patients were also given a questionnaire from the Scoliosis Research Society with 24 questions (SRS 24), ${ }^{20}$ translated into German, which measures the quality of life of scoliosis patients. The SRS 24 questionnaire is a disease-specific, reliable, and validated questionnaire used to assess outcomes in AIS. The questionnaire includes 24 questions, and the maximum possible score is 120 points, indicating that the patient is highly satisfied and asymptomatic. The questions represent seven major patient-based outcome domains; The responses are rated on a scale of 1 to 5 , with 5 being the optimal response. The domains included: pain ( 7 items, max 35 points), general self-image ( 3 items, 15 points), function from back condition ( 3 items, 15 points), general level of activity ( 3 items, 15 points), postoperative self-image ( 3 items, 15 points), postoperative function ( 2 items, 10 points) and satisfaction ( 3 items, 15 points).

The demographic data included 50 patients (44 women, 6 men), with an average age at the time of surgery of 16 years and 6 months (range 12 years and 5 months to 21 years and 8 months). The mean follow-up was 121.7 months or 10.14 years ( \pm 14.1 months, range 101 to 151 months). 49 of the 50 patients (98\%) accepted the invitation to follow-up; only one patient was living abroad and could not be contacted for the questionnaire, but the demographic data and the pre- and postoperative radiological results and those at the time of the last follow-up were included. Posterior fusion with the titanium instrumentation was performed in all cases. Additionally, 9 of 50 patients had anterior release preoperatively because of a severe main thoracic curve (average $81^{\circ}$, range $71^{\circ}$ to $111^{\circ}$ ). Average blood loss was $1980 \mathrm{ml}$ (range $600-4500 \mathrm{ml}$ ), and average operation time was $270 \mathrm{~min}$ (range 140 to $410 \mathrm{~min}$ ). Fusion with the WSI titanium included 10.0 (range 6 to 13) vertebrae on average. The average cephalic level of fusion was T 5.2 and the average caudal level of fusion was L 2.3. The two rods were fixed with a combination of hooks and pedicle screws only, with an average of 8.9 hooks and 4.2 screws per patient. A total of 424 hooks and 209 pedicle screws were inserted in 50 patients. The pedicle screws were inserted mainly in the lumbar region of the instrumentation. According to SRS terminology, there were 30 thoracic, 16 double, 2 thoracolumbar and 2 lumbar curves. According to the King classification, there were 2 patients with type I curves, 25 patients with type II curves, 9 patients with type III curves, 7 patients with type IV curves and 3 patients with type V curves. 4 patients could not be classified according to the King system.

SPSS Version 8 software for Windows was used for the statistical analysis, and the P values of $\leq 0.05$ were considered significant. Descriptive statistics were used to determine means, standard deviations (SD), and ranges. Comparisons between variables were performed using a Student's t test and the Kruskal-Wallis test.

\section{Results}

In the frontal plane, the mean preoperative thoracic curve was 62.4 degrees (range $32^{\circ}$ to $111^{\circ} ; \pm 14.1^{\circ}$ ). Postoperatively, the thoracic curve was 26.9 degrees (range $8^{\circ}$ to $58^{\circ} ; \pm 9.8^{\circ}$ ), equivalent to a correction rate of $56.9 \%$. At the most recent follow-up evaluation, the Cobb angle of the thoracic curve was 31.0 degrees (range $8^{\circ}$ to $58^{\circ} ; \pm 11.2^{\circ}$ ), equivalent to a final correction rate of $50.3 \%$. The mean preoperative lumbar curve was 43.5 degrees (range $18^{\circ}$ to $82^{\circ} ; \pm 14.9^{\circ}$ ). Postoperatively, the lumbar curve was 16.3 degrees (range $2^{\circ}$ to $36^{\circ} ; \pm 9.9^{\circ}$ ), equivalent to a correction rate of $62.5 \%$. At the most recent follow-up evaluation, the Cobb angle of the lumbar curve was 21.3 degrees (range $2^{\circ}$ to $55^{\circ} ; \pm 13.3^{\circ}$ ), equivalent to a final 
correction rate of $51.0 \%$. Average frontal balance as determined by mediolateral offset of the C7 vertebral body centre in relation to CSVL was $15.4 \mathrm{~mm} \pm 12.4$ preoperatively and $10.8 \pm$ $9.7 \mathrm{~mm}$ at the most recent follow-up. 16 of 50 patients (32\%) showed preoperative C7 offset of more than $20 \mathrm{~mm}$. At the most recent follow-up, 5 of 50 patients (10\%) showed frontal imbalance: 3 out of these 5 patients had preoperative imbalance and 2 patients showed preoperative regular frontal balance. Apical translation (apex of thoracic curve to CSVL) measured $51.7 \mathrm{~mm} \pm 26.2$ preoperatively, $18.7 \mathrm{~mm} \pm 14.7$ postoperatively, and $25.3 \mathrm{~mm} \pm$ 11.9 at the final follow-up, equivalent to a final correction rate of $51.1 \%$

In the sagittal plane, the average preoperative thoracic kyphosis angle (T5 to T12) curve was 19.8 degrees (range $2^{\circ}-63^{\circ}, \pm 14.5^{\circ}$ ). At the most recent follow-up, the thoracic kyphosis angle measured $25.8 \pm 12.3$ degrees. 4 patients had thoracic hyperkyphosis of more than 40 degrees preoperatively, and all of these patients still showed thoracic hyperkyphosis at the most recent follow-up.

3 out of 28 patients $(10.7 \%)$ with normal preoperative thoracic kyphosis developed minor hyperkyphosis of more than 40 degrees at the most recent follow-up (35 to $51^{\circ} ; 25$ to $46^{\circ}$; 26 to $45^{\circ}$ ). No one with preoperative flat back (18 patients with less than $10^{\circ}$ thoracic kyphosis) showed hyperkyphosis at the most recent follow-up. Moreover, the average preoperative lumbar lordosis angle (L1 to S1) curve was 56.1 degrees (range $32^{\circ}-90^{\circ}, \pm$ $\left.12.8^{\circ}\right)$. At the most recent follow-up, the lumbar lordosis angle measured $57.9 \pm 9.8$ degrees. 7 of 50 patients showed preoperative lumbar hyperlordosis of more than 70 degrees; at the most recent follow-up, 2 out of these 7 patients showed normal lordosis (between 40 and 70 degrees) and 5 patients had still hyperlordosis. No one with normal preoperative lumbar lordosis showed hyperlordosis of more than 70 degrees at the most recent follow-up.

There was no direct or indirect surgical mortality, and there were no permanent neurological complications. According to the medical files, 7 re-operations had to be performed: one patient developed incomplete postoperative paraparesis of the lower limb, so the implant had to be removed and the correction was immediately reverted on the first postoperative day. After complete neurological recovery, posterior reinstrumentation was performed 3 weeks later; at the time of follow-up the implant is in situ. We also saw one acute deep infection 3 weeks postoperatively with the detection of Staphylococcus aureus. The infection was cured by means of surgical debridement with the placement of a temporary suction/irrigation drain and targeted antibiotic therapy; the implant did not have to be removed and was likewise still in situ at the time of follow-up. Because of a loosened pedicle screw in the distal fusion region, a revision of the pedicle screw was performed 3 weeks postoperatively, and the implant was likewise in situ at the time of follow-up. In one patient, there was a distal loss of correction below the instrumentation at the level of L1, retrospectively due to an excessively short distal fusion, which did not include the caudal final vertebra of the curve. In this case, the extension of the posterior instrumentation as far as L3 was performed 22 months postoperatively, after an additional anterior release. Here, too, the implant was still in situ. Complete implant removal was performed in one patient 43 months postoperatively because of persistent back pain in the region of the instrumentation (LOSP). Intraoperatively, there was slight corrosion and there was no evidence of infection or pseudarthrosis. Re-instrumentation had to be performed in 2 patients 73 and 102 months 
postoperatively, respectively, because of radiological evidence of pseudarthrosis with loosening of the implant and loss of correction. In these two patients, the implant is also still in situ at the time of the follow-up. The complete re-operation rate is $14 \%$ ( 7 out of 50 patients). It must be emphasised that we did not see any late deep infection in any patient, and only one implant had been completely removed at the time of follow-up. We also recorded the following complications, which did not require revision: 8 patients had an asymptomatic hook dislocation, in each case in the distal region of the instrumentation. In 2 further patients there was a dislocation of the vertical rod, and in 4 further patients the last radiological follow-up showed an asymptomatic fracture of the vertical rod without a significant distraction of the fracture site as possible evidence of pseudarthrosis. One case of haemothorax was documented, which required a chest drain for several days. There was no case of pedicle screw fatigue fracture or fracture of a transverse connector rod.

In the SRS-24 questionnaire, the total score averaged 95.8 points out of a maximum of 120 points (min. 60 to max. 110 points, $\mathrm{SD} \pm 8.8$ ) at the final follow-up. In the questionnaire, 48 out of 49 patients $(98 \%)$ were highly or fairly satisfied (scores of 4 or 5 ) with the result of the back treatment; only one patient was somewhat dissatisfied. 42 out of 49 patients (86\%) reported never or rarely having back pain (score of 4 or 5) at rest. Only 3 out of $49(6.1 \%)$ patients had back pain often or very often. Overall 44 out of 49 patients (90\%) would definitely (36 patients with a score of 5 points) or probably (8 patients with a score of 4 points) undergo the same treatment again. Statistical analysis yielded the following results: 25 patients had a distal fusion segment from T12 to L2 inclusive, 24 patients had a distal fusion segment between L3 and L4 (L5 and sacrum were not fused). Both groups showed a nearly identical average SRS score (96.5 versus 95.0 points) with no significant difference ( $\mathrm{t}$ test 0.59 ). 20 patients had fusion of more than 11 vertebrae, 20 patients had fusion of 9 or 10 vertebrae, and 9 patients had fusion of less than 9 vertebrae. The three groups showed an average SRS score of 97.8 points versus 95.6 versus 91.6 points, respectively, with no significant difference. Within the individual classifications (SRS, King), no significant differences were found with regard to the subjective outcome. And there was no significant difference in the outcomes between the 6 male and 43 female patients in the study (average score 97.7 versus 95.5 points).

\section{Conclusions}

All together, this study presents the first long-term results with a titanium instrumentation for the treatment of AIS. 49 out of 50 patients (98\%) were clinically followed-up on over a mean period of 10.14 years post surgery via questionnaire and radiological imaging. Reoperation for all reasons was $14 \%$ : it was $2 \%$ for LOSP and $4 \%$ for pseudarthrosis. No permanent neurological deficits and no late infections were observed. The instrumentation shows stability; the loss of correction at the frontal thoracic and lumbar curve is low, with a correction rate of $50.3 \%$ and $51.0 \%$ at the most recent follow-up. In the frontal plane, only 2 patients developed decompensation and 3 patients showed proximal junctional hyperkyphosis in the sagittal plane at follow-up. No screw fracture and no transverse connector fracture were detected. The survival rate of the implant is very high; $98 \%$ of the implants are still in situ. $98 \%$ of the patients were very or fairly satisfied with the result; $86 \%$ of the patients never or rarely have back pain at rest. 


\begin{tabular}{|c|c|c|c|c|}
\hline $\begin{array}{c}\text { Year of } \\
\text { publication }\end{array}$ & Authors & Instrumentation & No. of patients & Re-operation rate $\%$ \\
\hline 2009 & Mueller & WSI & $0 / 50$ & 0 \\
\hline 2008 & Rihn & $?$ & $6 / 236$ & 2.5 \\
\hline 2005 & Hahn & USS & $5 / 67$ & 7.5 \\
\hline 2004 & Remes & USS & $4 / 55$ & 7.2 \\
\hline 2004 & Remes & CD & $3 / 57$ & 5.3 \\
\hline 2003 & Bago & CD & $10 / 113$ & 8.8 \\
\hline 2003 & Helenius & CD & $3 / 57$ & 5.3 \\
\hline 1999 & Clark & CD & $21 / 917$ & 2.3 \\
\hline 1995 & Richards & TSHR & $10 / 149$ & 6.7 \\
\hline
\end{tabular}

Table 3. Re-operation rates due to late infection in the literature.

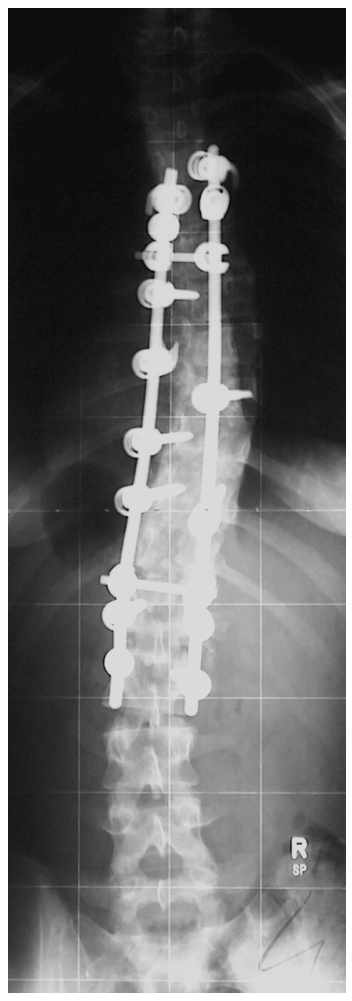

Fig. 3. X-ray of titanium instrumentation with hooks and pedicle screws.

\subsection{Review of other posterior instrumentations}

2011 In a prospective, multicentre cohort study with data from 6 scoliosis centres in the USA, the outcome of 745 surgical patients was evaluated 2 years after surgery (Carreon et al., 2011). There were 622 female and 123 male patients with a mean age of 14.2 years and a mean Cobb angle of $54^{\circ}$. The result showed a statistically significant difference between paired preoperative and 2 year postoperative SRS-22 domain scores, but there were low to 
moderate associations between the change in any of the domain scores and patients satisfaction with the treatment. Moreover, there was no statistically significant correlation between the 2-year postoperative SRS satisfaction score and the amount of curve correction.

The authors conclude that this may be because of the ceiling effect in the satisfaction domain, the lack of responsiveness of the SRS-22 to measure clinically relevant changes in activity, pain and mental health or a true lack of change in these domains.

(2007) In 2007, Benli et al. published their results on a posterior implant, the so-called Texas Scottish Rite Hospital System (TSHR), which is an instrumentation similar to the CD.

In their study (Benli et al, 2007), the surgical results of 109 idiopathic scoliosis patients, treated between 1991 and 1994 were evaluated. The mean follow-up period was 137 months, with a minimum of 10 years post surgery. The mean age of patients at the time of surgery was 14.4 years. Postoperatively, no cast or brace was utilised. The initial correction rate of the major curve was $64 \%$, with a correction loss of $10.3^{\circ}$ at the last follow-up. About 10 out of 109 patients (9.2\%) were considered to have pseudarthrosis: 4 patients with instrumentation failure and 6 patients with a correction loss over $15^{\circ}$ at the frontal plane. These 10 patients underwent re-operation. Overall, the average scores of the SRS-22 questionnaire for general self-image, function, mental status, pain, and satisfaction with the treatment were 3.8, 3.6, 4.0, 3.6, and 4.6, respectively, at the last follow-up. The pain scores were not correlated with the curve types, final Cobb angles, or the amount of correction loss.

The authors' therefore, concluded that the instrumentation is efficient for the correction of frontal and sagittal plane deformities and trunk balance resulting in a better quality of life.

2001 In 2001, Parsch et al. reported about the effect of multisegmental spinal fusion on the long-term functional and radiological outcome compared to patients whose spine had not been fused, and to a control group (Parsch et al., 2001). They studied 68 patients with AIS (34 with and 34 without surgery, respectively) who had been followed-up for a minimum of 5 years after treatment. An age- and gender-matched control group of 34 patients was also recruited. The study was based on a non-validated questionnaire introduced by Connolly in 1995, an individual assessment of chronic back pain using a numerical rating scale and an evaluation of radiographs.

The results of the spinal score showed no significant difference between fused and unfused patients. However, compared with the healthy control group, a significant lower score was demonstrated for both scoliosis groups. They concluded that multisegmental spinal fusion does not have an adverse effect on the long-term functional outcome, or on the frequency and severity of back pain in patients with AIS compared with unfused patients. However, patients with AIS have a worse long-term spinal function, and a greater frequency and severity of back pain when compared with healthy age-matched controls.

It is a critical aspect that only a small number of patients and data, respectively, were collected from as many as 8 hospitals. Furthermore, the authors failed to provide precise empirical data with regard to treatment measures, such as the type of instrumentations or the possible application of corset treatment in non-surgical patients. In addition, given a follow-up time of 5 years, the results cannot be considered long-term results. 


\section{Long-term outcome of anterior instrumentation}

\subsection{Background to anterior instrumentation}

Open anterior spinal instrumentation with fusion for adolescent idiopathic scoliosis has its origins with Dwyer and Zielke (Dywer et al., 1969; Zielke et al., 1976), who developed anterior instrumentation for thoracolumbar and lumbar scoliosis. The approach offers the ability to fuse a small number of vertebral segments, thereby protecting more lumbar motion segments. Moreover, anterior correction can theoretically achieve a higher correction rate in the coronal plane. On the other side, if there is substantial growth in the adolescent spine, anterior fusion can lead to hyperkyphosis.

\subsection{Review on anterior instrumentation}

2010 Lately, Kelly et al. published a retrospective review on the long-term clinical and radiographic outcomes of open anterior spinal fusion with instrumentation for thoracolumbar and lumbar curves. During an 11-year period between 1984 and 1995, overall only 31 patients underwent anterior instrumentation and fusion with 3 different systems (Dwyer, TSRH, and Zielke) at one single centre (the University Hospital Memphis, USA) performed by the senior author only (Kelly et al., 2010).

18 out of 3 patients (58\%) were still available for review with an average follow-up of nearly 19 years (range 12 to 22 years). The instrumented thoracolumbar curves were corrected from an average of $49^{\circ}$ before to $19^{\circ}$ after surgery and $25^{\circ}$ at long-term follow-up. The uninstrumented thoracic curves were corrected from an average of $34^{\circ}$ before surgery, to $25^{\circ}$ at follow-up and $24^{\circ}$ at a long-term follow-up. No progression occurred in the uninstrumented thoracic curve. Based on the SRS-30 questionnaire and the Oswestry Disability Index, most patients had good function scores and acceptable pain levels. The SRS-30 score was 98 out of a maximum of 115 points. The surgical satisfaction score was $9.3 / 10$, and most patients stated that they were pleased with the result and would have the same procedure again. Instrumentation failure was identified in 2 patients, but without the detection of pseudarthrosis. Changes of early degenerative disc disease on plain radiographs and MRI were identified in most patients but had no correlation with SRS and Oswestry data.

Therefore, the authors concluded that anterior surgery offers good long-term functional outcomes.

1997 More than 10 years earlier, Otani et al. from Tokyo, Japan, represented the long-term follow-up results after open anterior instrumentation for the first time (Otani et al., 1997). The study represented a retrospective follow-up of an average period of 14.6 years. 134 patients with idiopathic scoliosis were treated between 1973 and 1993, and 53 out of 134 patients $(39 \%)$ were followed for a minimum of 10 years. Dwyer instrumentation was used in 17 and Zielke in 36 cases, respectively. The curve was thoracic in 16, thoracolumbar in 27 and lumbar in 10 . The average preoperative Cobb angle was $64^{\circ}$. The average angle at follow-up was $21^{\circ}$ with $62 \%$ of the average correction maintained $(61 \% /$ Dwyer and $65 \% /$ Zielke). 
The authors reflected that most patients were satisfied subjectively and, therefore, they recommend this type of operation.

\section{Conclusions}

Summarising, the following statements regarding long-term results in the surgical treatment of adolescent idiopathic scoliosis can be made:

Operative correction and stabilisation of scoliosis using instrumentation started with the development, utilisation, and worldwide propagation of a rod and hook system and, 50 years ago, Harrington PR was the first to publish a scientific paper on this in 1962.

The development of the Harrington rod was based on the analyses of scoliosis in poliomyelitis patients, rather than on adolescent idiopathic scoliosis.

Frontal corrections using the Harrington rod required the application of an additional corset, which had to be worn for 6 to 12 months after surgery, for external immobilisation in order to avoid loss of correction.

Most of the scientific publications regarding the long-term results on the surgical treatment of adolescent idiopathic scoliosis investigated this instrumentation.

All of these studies are characterised by low levels of evidence (evidence level 3 and 4), small numbers of patients, and a high loss to follow-up.

In the medium and long term, many Harrington rods were removed with only insufficient data and without providing precise reasons for this.

Radiological findings have shown a mostly significant loss of correction and a flattening of the spinal profile.

Quality of life does not directly correlate with radiological parameters such as correction rate or length of fusion.

However, there is a long-term tendency of patients suffering from increased back pain.

In addition, there is a tendency suggesting that shorter spondylodeses and instrumentations, respectively, result in clinically improved outcome.

A few so-called cohort studies mainly showed a clinically high quality of life after Harrington rod correction when compared to healthy populations.

25 years ago, Cotrel and Dubousset were the first to publish research on a segmentstabilising rod system, which was designed to eliminate the disadvantages of the Harrington rod; in particular, it did not require corset treatment over several months, due to its high primary stability.

Proprietary long-term results after correction using CD instrumentations also show a high complication rate, particularly fistulae and infections.

The few retrospective long-term studies (evidence level 3 and 4) showed a significant higher correction rate and a lower loss of correction over time in favour of the CD system when compared to the Harrington rod. 
Until now, no significant differences between the Harrington rod and the CD system have been observed with regard to the clinical long-term outcome.

Based on rapid advancements that have been achieved in implant design during the last 10 to 20 years, the Harrington rod - which was the implant of choice - has been gradually abandoned and has been considered obsolete in the meantime.

Long-term results for newer instrumentations in larger patient populations are currently missing. The question of whether improved clinical results can be achieved despite a lower number of fused segments, remains currently unanswered.

After an average follow-up of 10 years, our own study using a new generation titanium instrumentation showed at least clinically and radiologically equivalent results for the first 50 consecutive patients when compared to both of the instrumentations mentioned above.

And all instrumentations were still in situ at the time of the follow-up.

The term "long-term follow-up" has not been defined until now. Since patients - based on their young age - require a long follow-up period even at the beginning of the treatment, we suggest follow-up periods of at least 10 or even 20 years after the completion of the treatment, particularly when considering the data of our own studies.

However, one must not expect final results in adolescent idiopathic scoliosis, due to lifelong clinical and radiological changes of the scoliotic vertebral column - with or without instrumentations.

It remains a hypothetical question, if and when patients after surgical correction are equivalent to so-called healthy populations.

Results from randomised prospective studies are still missing.

We will see in the future, whether currently available, clinically evaluated tools such as the SRS Questionaire, SF-36, or other health-related questionnaires are sufficient to assess the quality of life in scoliosis patients, or if these questionnaires will be modified or replaced within the next few years.

Last but not least, a randomised prospective multicentre study with three levels (natural course versus corset treatment only versus surgical procedure) is ethically justified and urgently required face to currently available data.

\section{References}

Aaro, S. \& Dahlborn, M. (1982). The effect of Harrington instrumentation on the longitudinal axis rotation of the apical vertebra and on the spinal and rib-cage deformity in idiopathic scoliosis studied by computer tomography. Spine, Vol. 7, No. 5, (September/October 1982), pp. 456-462, ISSN 0362-2436

Ameri , E. ; Behtash, H. ; Mobini, B. ; Omidi-Kashani, F. \& Momeni, B. (2008). Radiographic outcome of surgical treatment of adolescent idiopathic scoliosis in males versus females. Scoliosis, Vol. 3, No. 12, (September 6, 2008), ISSN 1748-7161 
Asher; M.; Min Lai, S.; Burton, D. \& Manna, B. (2003) Discrimination validitiy of the Scoliosis Research Society-22 patient questionnaire: relationship to idiopathic scoliosis curve pattern and curve size. Spine, Vol. 28, No. 1, (January 1, 2003), pp. 74-77, ISSN 0362-2436

Asher, M.; Lai, SM. ; Burton, D. ; Manna, B. \& Cooper, A. (2004). Safety and efficacy of Isola instrumentation and arthrodesis for adolescent idiopathic scoliosis. Two- to 12-year follow up. Spine, Vol. 29, No. 18, (September 15, 2004), pp. 2013-2023, ISSN 03622436

Bago, J.; Ramirez, M.; Pellise, F. \& Villanueva, C. (2003). Survivorship analysis of CotrelDubousset instrumentation in idiopathic scoliosis. European Spine Journal, Vol. 12, No. 4, (June 21, 2003), pp. 435-439, ISSN 0940-6719

Benli, IT.; Ates, B.; Akalin, S.; Citak, M.; Kaya, A. \& Alanay, A. (2007). Minimum 10 years follow up surgical results of adolescent idiopathic scoliosis patients treated with TSRH instrumentation. European Spine Journal, Vol. 16, No. 3, (March 2007), pp. 381391, ISSN 0940-6719

Bjerkreim, I. ; Steen, H. \& Brox, JI. (2007). Idiopathic scoliosis treated with Cotrel-Dubousset instrumentation. Evaluation 10 years after surgery. Spine, Vol. 32, No. 19, (September 1, 2007), pp. 2103-2110, ISSN 0362-2436

Boss, N. ; Dolan, LA. \& Weinstein, SL. (2007). Long term clinical and radiographic results of Cotrel-Dubousset instrumentation of right thoracic adolescent scoliosis. Iowa Orthopedic Journal, Vol. 27, pp. 40-46

Bridwell, KH.; Shufflebarger, HL. ; Lenke, LG.; Lowe, TG. ; Betz, RR. \& Bassett, GS. (2000) Parents' and patients' preference and concerns in idiopathic adolescent scoliosis : a cross-sectional preoperative analysis. Spine, Vol. 25, No. 18, (September 15, 2000), pp. 2392-2399, ISSN 0362-2436

Bridwell, KH.; Cats-Baril, W.; Harrast, J.; Berven, S.; Glassman, S.; Farcy, JP.; Horton, WC.; Lenke, LG.; Baldus, C. \& Radake, T. (2005) The validity of the SRS-22 instrument in an adult spinal deformity population compared with the Oswestry and SF-12: a study of response distribution, concurrent validity, internal consistency and reliability. Spine, Vol. 30, No. 4, (February 15, 2005), pp. 455-461, ISSN 0362-2436

Carreon, LY.; Sanders, JO.; Diab, M.; Sturm, PF.; Sucato, DJ.; the Spinal Deformity Study Group. (2011). Patient satisfaction after surgical correction of adolescent idopathic scoliosis. Spine, Vol. 36, No. 12, (May 20, 2011), pp. 965-968, ISSN 0362-2436

Clark, CE. \& Shufflebarger, HL. (1999). Late-developing infection in instrumented idiopathic scoliosis. Spine, Vol. 24, No. 18, (September 15, 1999), pp. 1909-1912, ISSN 0362-2436

Cobb, JR. (1948). Outline for the study of scoliosis. In: Instructional Course Lectures, The American Academy of Orthopaedic Surgeons. Vol. 5, pp. 261-275. Ann Arbor, J. W. Edward, 1948

Cochran, T.; Irstam, L. \& Nachemson, A. (1983). Long term anatomic and functional changes in patients with adolescent idiopathic scoliosis treated by Harrington rod fusion. Spine, Vol. 8, No. 6, (September 1983), pp. 576-584, ISSN 0362-2436

Connolly, PJ.; Von Schroeder, HP.; Johnson, GE. \& Kostuik, JP. (1995). Adolescent idiopathic scoliosis. Long-term effect of instrumentation extending to the lumbar spine. The Journal of Bone and Joint Surgery American, Vol. 77, No. 8, (August 1995), pp. 12101216, ISSN 1535-1386

Cook, S.; Asher, M.; Lai, SM. \& Shobe J. (2000). Reoperation after primary posterior instrumentation and fusion for idiopathic scoliosis. Spine, Vol. 25, No. 4, (February 2000), pp. 463-468, ISSN 0362-2436 
Cotrel, Y. \& Dubousset, J. (1984). Nouvelle technique d’ostheosynthèse rachidienne sègmentaire par voie postèrieure. Rev Chir Orthop Reparatrice Appar Mot, Vol. 70, No. 6, pp. 489-495

Cundy, PJ.; Paterson, DC.; Hillier, TM.; Sutherland, AD.; Stephen, JP. \& Foster, BK. (1990). Cotrel-Dubousset instrumentation and vertebral rotation in adolescent idiopathic scoliosis. The Journal of Bone and Joint Surgery British, Vol. 72, No. 4, (July 1990), pp. 670-674, ISSN 0301-620X

Danielsson, AJ.; Wiklund, I.; Pehrsson, K. \& Nachemson, AL. (2001). Health-related quality of life in patients with adolescent idiopathic scoliosis: a matched follow-up at least 20 years after treatment with brace or surgery. European Spine Journal, Vol. 10, No. 4, (August 2001), pp. 278-288, ISSN 0940-6719

Dickson, JH. \& Harrington, PR. (1973). An eleven-year clinical investigation of Harrington instrumentation. A preliminary report of 578 cases. Clinical Orthopaedics and Related Research, Vol. 93, No. 6, (June 1973), pp. 113-130, ISSN 0009-921X

Dickson, JH.; Erwin, WD. \& Rossi, D. (1990). Harrington instrumentation and arthrodesis for idiopathic scoliosis. A twenty-one-year follow up. The Journal of Bone and Joint Surgery American, Vol. 72, No. 5, (June 1, 1990), pp. 678-683, ISSN 1535-1386

Dwyer, AF.; Newton, NC. \& Sherwood, AA. (1969). An anterior approach to scoliosis. A preliminary report. Clinical Orthopaedics and Related Research, Vol. 62, No. 1; (January/February, 1969), pp. 192-202, ISSN 0009-921X

EuroQol Group. (1990). EuroQol: a new facility for the measurement of health related quality of life. Health Policy, Vol. 16, No. 3, (December 1990), pp. 199-208, ISSN 0168-8510

Fairbank, JC.; Couper, J.; Davis, JB. \& O`Brien, JP. (1980). The Oswestry low back pain disablitiy questionnaire. Physiotherapy, Vol. 66, No. 8, (August, 1980), pp. 271-273, ISSN 0031-9406

Goetze, C.; Liljenqvist, UR.; Slomka, A.; Goetze, HG. \& Steinbeck, J. (2002). Quality of life and back pain: Outcome 16.7 years after Harrington instrumentation. Spine, Vol. 27, No. 13, (July 1, 2002), pp. 1456-1463, ISSN 0362-2436

Haher, TR.; Merola, A.; Zipnick, RI.; Gorup, J.; Mannor, D. \& Orchowski, J. (1995). Metaanalysis of surgical outcome in adolescent idiopathic scoliosis. A 35-year English literature review of 11,000 patients. Spine, Vol. 20, No. 14, (July 1995), pp. 1575-1584, ISSN 0362-2436

Haher, TR.; Gorup, JM.; Shin, TM.; Homel, P.; Merola, AA.; Grogan, DP.; Pugh, L.; Lowe, TG. \& Murray; M. (1999). Results of the Scoliosis Research Society instrument for evaluation of surgical outcome in adolescent idiopathic scoliosis: a multicenter study of 244 patients. Spine, Vol. 24, No. 14, (July 15, 1999), pp. 1435-1440, ISSN 0362-2436

Hahn, F.; Zbinden, R. \& Min, K. (2005). Late implant infections caused by Propionibacterium acnes in scoliosis surgery. European Spine Journal, Vol. 14, No. 8, (October 2005), pp. 783-788, ISSN 0940-6719

Halm, H.; Niemeyer, T.; Link, T. \& Liljenqvist, U. (2000). Segmental pedicle screw instrumentation in idiopathic thoracolumbar and lumbar scoliosis. European Spine Journal, Vol. 9, No. 3, (June, 2000), pp.191-197, ISSN 0940-6719

Harrington, PR. (1962). Treatment of scoliosis. Correction and internal fixation by spine instrumentation. Journal of Bone Joint Surgery Am, Vol. 44, No. 6, (June 1962), pp. 591-610, ISSN 1535-1368

Helenius, I.; Remes,V.; Yrjönen, T.; Ylikoski, M.; Schlenzka, D.; Helenius, M. \& Poussa, M. (2003) Harrington and Cotrel-Dubousset instrumentation in adolescent idiopathic 
scoliosis. Long-term functional and radiographic outcomes. The Journal of Bone Joint Surgery American, Vol. 85, No. 12, (December 2003), pp. 2303-2309, ISSN 1535-1368

Hibbs, RA. (1924). A report of fifty-nine cases of scoliosis treated by the fusion operation. The Journal of Bone Joint Surgery American, Vol. 6, No. 1, (January 1, 1924) pp. 3-34, ISSN 1535-1368

Humke, T.; Grob, D.; Scheier, H. \& Siegrist, H. (1995). Cotrel-Dubousset and Harrington Instrumentation in idiopathic scoliosis: a comparison of long-term results. European Spine Journal, Vol. 4, No. 5, (October 1995), pp. 280-283, ISSN 0940-6719

Kahanovitz, N. \& Weiser, S. (1989). The psychological impact of idiopathic scoliosis on the adolescent female. A preliminary multi-center study. Spine, Vol. 14, No. 5, (May 1989), pp. 483-485, ISSN 0362-2436

Kelly, DM.; McCarthy, RE.; McCullough, FL. \& Kelly, HR. (2010). Long-term outcomes of anterior spinal fusion with instrumentation for thoracolumbar and lumbar curves in adolescent scoliosis. Spine, Vol. 35, No. 2, (January 15, 2010), pp. 194-198, ISSN $0362-2436$

King, HA.; Moe, JH.; Bradford, DS. \& Winter, RB. (1983). The selection of fusion levels in thoracic idiopathic scoliosis. The Journal of Bone and Joint Surgery American, Vol. 65, No. 9, (December 1983), pp. 1302-1313, ISSN 1535-1368

Lea Plaza, CA.; Karsaclian, M. \& Rocca, C. (2004). Segmental scoliosis correlation: use of the Lea Plaza frame. Spine, Vol. 29, No. 4, (February 15, 2004), pp. 398-404, ISSN 0362-2436

Lenke, LG. ; Bridwell, KH. ; Blanke, K. ; Baldus, C. \& Weston, J. (1998). Radiographic results of arthrodesis with Cotrel-Dubousset instrumentation for the treatment of adolescent idiopathic scoliosis. A five to ten-year follow-up study. The Journal of Bone and Joint Surgery American, Vol. 80, No. 6, (June 1998), pp. 807-814, ISSN 1535-1368

Liljenqvist, UR.; Bullmann, V.; Schulte, TL.; Hackenberg, L. \& Halm, HF. (2006). Anterior dual rod instrumentation in idiopathic thoracic scoliosis. European Spine Journal, Vol. 15, No. 7; (July 2006), pp. 1118-1127, ISSN 0940-6719

Lonner, BS.; Kondrachov, D.; Siddiqi, F.; Hayes, V. \& Scharf, C. (2006). Thoracoscopic spinal fusion compared with posterior spinal fusion for the treatment of thoracic adolescent idiopathic scoliosis. The Journal of Bone Joint Surgery American, Vol. 88, No. 5, (May 2006), pp. 1022-1034, ISSN 1535-1368

Luque, ER. (1982). Segmental spinal instrumentation for correction of scoliosis. Clinical Orthopaedics and Related Research, Vol. 163, No. 3, (March 1982), pp. 192-198, ISSN 0009-921X

Mariconda, M.; Galasso, O.; Barca, P. \& Milano, C. (2005). Minimum 20-year follow-up results of Harrington rod fusion for idiopathic scoliosis. European Spine Journal, Vol. 14, No. 9, (November 2005), pp. 854-861, ISSN 0940-6719

Merola, AA.; Haher, TR.; Brkaric, M.; Panagopoulos, G.; Mathur, S.; Kohani, O.; Lowe, TG.; Lenke, LG.; Wenger, DR.; Newton, PO.; Clements, DH III. \& Betz, RR. (2002). A multicenter study of adolescent idiopathic scoliosis using the Scoliosis Research Society (SRS) outcome instrument. Spine, Vol. 27, No. 18, (September 15, 2002), pp. 2046-2051, ISSN 0362-2436

Mueller, FJ. \& Gluch, H. (2009) Adolescent idiopathic scoliosis (AIS) treated with arthrodesis and posterior instrumentation: 8 to 12 years follow up without late infection. Scoliosis, Vol. 4, No. 16, ISSN 1748-7161

Otani, K.; Saito, M. \& Sibasaki K. (1997). Anterior instrumentation in idiopathic scoliosis: a minimum follow-up of 10 years. International Orthopaedics, Vol. 21, No. 1, (January 1997), pp. 4-8, ISSN 0341-2695 
Padua, R.; Padua, S.; Aulisa, L.; Ceccarelli, E.; Padua, L.; Romanini, E.; Zanoli, G. \& Campi, A. (2001). Patient outcomes after Harrington instrumentation for idiopathic scoliosis: a 15- to 28- year evaluation. Spine, Vol. 26, No. 11, (June 1, 2001), pp. 12681273, ISSN 0362-2436

Parsch, D.; Gaertner, V.; Brocai, DR. \& Carstens, C. (2001). The effect of spinal fusion on the longterm outcome of idiopathic scoliosis. A case-control study. The Journal of Bone and Joint Surgery British, Vol. 83, No. 8, (November 2001), pp. 1133-1136, ISSN 0301-6207

Payne, WK III.; Ogilvie, JW.; Resnick, MD.; Kane, RL.; Transfeldt, EE. \& Blum, RW. (1997) Does scoliosis have a psychological impact and does gender make a difference? Spine, Vol. 22, No. 12, (June 1997), pp. 1380-1384, ISSN 0362-2436

Reddi, V.; Clarke, DV. \& Arlet, V. (2008). Anterior thoracoscopic instrumentation in adolescent idiopathic scoliosis: a systematic review. Spine, Vol. 33, No. 18, (August 15, 2008), pp. 1986-1994, ISSN 0362-2436

Remes, V.; Helenius, I.; Schlenzka, D.; Yrjönen, T.; Ylikoski, M. \& Poussa, M. (2004). CotrelDubousset (CD) or Universal Spine System (USS) instrumentation in adolescent idiopathic scoliosis (AIS): comparison of midterm clinical, functional, and radiologic outcomes. Spine, Vol. 29, No. 18, (September 15, 2004), pp. 2024-2030, ISSN 0362-2436

Richards, BS. (1995). Delayed infections following posterior spinal instrumentation for the treatment of idiopathic scoliosis. The Journal of Bone of Joint Surgery American, Vol. 77, No. 4, (April 1995), pp. 524-529, ISSN 1535-1368

Rihn, JA.; Lee, JY. \& Ward, WT. (2008). Infection after the surgical treatment of adolescent idiopathic scoliosis. Spine, Vol. 33, No. 3, (February 1, 2008), pp. 289-294, ISSN 0362-2436

Takahashi, S.; Delecrin, J. \& Passuti, N. (1997) Changes in the unfused lumbar spine in patients with idiopathic scoliosis. A 5- to 9-year assessment after cotrel-dubousset instrumentation. Spine, Vol. 22, No. 5, (March 1, 1997), pp. 517-523, ISSN 0362-2436

Ware, JE Jr. \& Sherbourne, CD. (1992) The MOS 36-item short-form health survey (SF-36). I. Conceptual framework and item selection. Medical Care, Vol. 30, No. 6, (June 1992), pp. 473-483, ISSN 0025-7079

Weatherley, CR.; Draycott, V.; O' Brien, JF.; Benson, DR.; Gapalakishnan, KG.; Evans, JH. \& O'Brien, JP. (1987). The rib deformity in adolescent idiopathic scoliosis: A prospective study to evaluate changes after Harrington distraction and posterior fusion. The Journal of Bone and Joint Surgery British, Vol. 69, No. 2, (March 1987), pp. 179-182, ISSN 0940-6719

Weigert, KP.; Nygaard, LM.; Christensen, FB.; Hansen, ES. \& Bünger, C. (2006) Outcome in adolescent idiopathic scoliosis after brace treatment and surgery assessed by means of the Scoliosis Research Society instrument 24. European Spine Journal, Vol. 15, No. 7, (July 15, 2006), pp. 1108-1117, ISSN

Weiss, HR. (2008). Adolescent idiopathic scoliosis (AIS) - an indication for surgery? A systematic review of the literature. Disability and Rehabilitation, Vol. 30, No. 10, (January 2008) pp. 799-807, ISSN 0963-8288

Wimmer, C. \& Gluch, H. (1998). Aseptic loosening after CD instrumentation in the treatment of scoliosis: A report about eight cases. Journal of Spinal Disorders \& Techniques, Vol. 11, No. 5, (October 1998), pp. 440-443, ISSN 1536-0652

Zhang, J.; He, D.; Gao, J.; Yu, X.; Sun, H.; Chen, Z. \& Li, M. (2011). Changes in life satisfaction and self-esteem in patients with adolescent idiopathic scoliosis with and without surgical intervention. Spine, Vol. 36 ; No. 9, (April 20, 2011), pp. 741745, ISSN 0362-2436

Zielke, K.; Stunkat, R. \& Beajean F. (1976). Ventrale derotations-spondylodesis. Archiv für Orthopädische und Unfall-Chirurgie, Vol. 85, No. 3, (August 1976), pp. 257-277 (Article in the German language) 


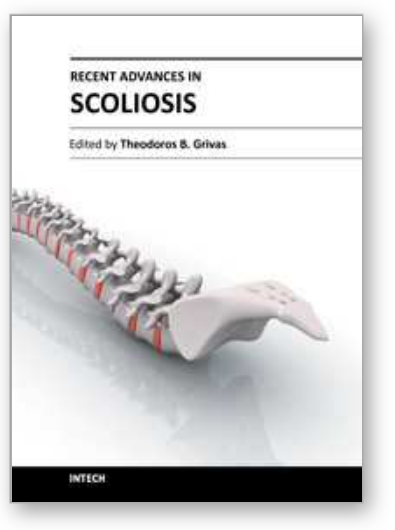

\author{
Recent Advances in Scoliosis \\ Edited by Dr Theodoros Grivas
}

ISBN 978-953-51-0595-4

Hard cover, 344 pages

Publisher InTech

Published online 09, May, 2012

Published in print edition May, 2012

This book contains information on recent advances in aetiology and pathogenesis of idiopathic scoliosis, for the assessment of this condition before treatment and during the follow-up, making a note of emerging technology and analytical techniques like virtual anatomy by 3-D MRI/CT, quantitative MRI and Moire Topography. Some new trends in conservative treatment and the long term outcome and complications of surgical treatment are described. Issues like health related quality of life, psychological aspects of scoliosis treatment and the very important "patient's perspective" are also discussed. Finally two chapters tapping the untreated early onset scoliosis and the congenital kyphoscoliosis due to hemivertebra are included. It must be emphasized that knowledgeable authors with their contributions share their experience and enthusiasm with peers interested in scoliosis.

\title{
How to reference
}

In order to correctly reference this scholarly work, feel free to copy and paste the following:

Franz Josef Mueller, Herbert Gluch and Cornelius Wimmer (2012). Long-Term Outcome of Surgical Treatment in Adolescent Idiopathic Scoliosis, Recent Advances in Scoliosis, Dr Theodoros Grivas (Ed.), ISBN: 978-95351-0595-4, InTech, Available from: http://www.intechopen.com/books/recent-advances-in-scoliosis/long-termoutcome-of-surgical-treatment-in-adolescent-idiopathic-scoliosis

\section{INTECH}

open science | open minds

\author{
InTech Europe \\ University Campus STeP Ri \\ Slavka Krautzeka 83/A \\ 51000 Rijeka, Croatia \\ Phone: +385 (51) 770447 \\ Fax: +385 (51) 686166 \\ www.intechopen.com
}

\author{
InTech China \\ Unit 405, Office Block, Hotel Equatorial Shanghai \\ No.65, Yan An Road (West), Shanghai, 200040, China \\ 中国上海市延安西路65号上海国际贵都大饭店办公楼 405 单元 \\ Phone: +86-21-62489820 \\ Fax: $+86-21-62489821$
}


(C) 2012 The Author(s). Licensee IntechOpen. This is an open access article distributed under the terms of the Creative Commons Attribution 3.0 License, which permits unrestricted use, distribution, and reproduction in any medium, provided the original work is properly cited. 